\title{
Eurolntervention
}

\section{Coating irregularities of durable polymer-based drug-eluting stents as assessed by scanning electron microscopy}

\author{
Mounir W.Z. Basalus ${ }^{1}$, MD; Marc J.K. Ankone ${ }^{2}$, MSc; K. Gert van Houwelingen ${ }^{1}$, MD;
} Frits H.A.F de Man', MD, PhD; Clemens von Birgelen ${ }^{1,2 *}$, MD, PhD

1. Department of Cardiology, Thoraxcentrum Twente, Enschede, The Netherlands; 2. Institute for Biomedical Technology (BMTI), University of Twente, Enschede, The Netherlands

\section{KEYWORDS}

Drug-eluting stents, percutaneous coronary interventions, polymer coating, scanning electron microscopy, coronary artery disease

\begin{abstract}
Aims: To classify and quantify post-expansion irregularities in durable polymer-based coatings of drugeluting stents (DES).

Methods and results: Taxus Liberté ${ }^{\mathrm{TM}}$, Endeavor Sprint ${ }^{\mathrm{TM}}$, Endeavor Resolute ${ }^{\mathrm{TM}}$ and Xience $\mathrm{V}^{\mathrm{TM}} \mathrm{DES}$ (three samples of each) were explored by light microscopy and scanning electron microscopy (SEM) following expansion at $14 \mathrm{~atm}$ in water. Incidence and size of irregularities were measured during thorough quantitative examinations of a 360 SEM images. DES types examined showed a significant difference in the incidence of irregularities ( $p<0.0001 ; 6.6 \pm 4.2$ /image at 60 -fold magnification) with typical patterns specific for each DES. All types showed areas with bare metal-aspects, but incidence, shape, and size differed largely: Sprint showed the largest areas. Cracks were only found in Sprint and Resolute, while wrinkles were seen exclusively in Taxus Liberté and Xience $V(p<0.0001)$. The coating of each DES type showed some inhomogeneity of distribution, but the incidence differed $(p<0.0001)$ and was least in Taxus Liberté, which, on the other hand, was the only DES that showed webbing with large bare-metal exposure.

Conclusions: The incidence and size of various coating irregularities on different types of DES varied widely. These data may be considered in ongoing discussions on the differences between DES and may serve as reference to compare novel DES.
\end{abstract}

* Corresponding author: Thoraxcentrum Twente, Department of Cardiology Haaksbergerstraat 55, 7513ER Enschede, The Netherlands

E-mail: c.vonbirgelen@ziekenhuis-mst.nl 


\section{Abbreviations \\ DES drug-eluting stent \\ SEM scanning electron microscopy \\ BMS bare metal stent}

\section{Introduction}

Drug-eluting stents (DES) represent a successful therapeutic strategy to minimise the rate of restenosis and the need for repeat revascularisation procedures compared to bare metal stents (BMS). ${ }^{1-4}$ However, this success is somewhat overshadowed by the ongoing debates on whether DES decrease mortality ${ }^{5-8}$ and on the incidence of late and very late stent thrombosis in DES. ${ }^{9}$ In the meantime, high-risk patient subsets have been identified, and DES implantation technique and antiplatelet regimen have been optimised to reduce the risk of DES thrombosis. ${ }^{10}$

The surface of the coating on DES, which incorporates and delivers the drug to the target area, can also promote thrombus formation, as irregularities and defects on the coating surface may increase roughness of the stent surface. ${ }^{11}$ In addition, endothelialisation of the DES struts is delayed (versus BMS) and sometimes incomplete, which results in a longer - and sometimes even persistent exposure of DES coating to blood.

Scanning electron microscopy (SEM) is a technique which allows us to closely examine the coating surface of DES, but until now only a very few SEM studies addressed the post-expansion morphology of DES. ${ }^{12,13}$ Otsuka et al demonstrated in a descriptive SEM-study the presence of defects in polymer coatings of primarily early generation DES. ${ }^{13}$ Several novel DES have appeared in the meantime. In the present study, we used SEM to thoroughly study the post-expansion morphology of the coating layer on four types of DES. The aim of our study was to classify post-expansion irregularities in the polymer coatings and to determine their frequency and dimensions.

\section{Methods}

\section{DES samples examined}

We examined four types of DES which all share the presence of a durable-polymer component. A total of 12 DES was examined: three Taxus Liberté ${ }^{\mathrm{TM}}$ (Boston Scientific Corp., Natick, MA, USA), three Endeavor Sprint ${ }^{\mathrm{TM}}$ (Medtronic Vascular, Santa Rosa, CA, USA), three Endeavor Resolute ${ }^{\mathrm{TM}}$ (Medtronic Vascular, Santa Rosa, CA, USA), and three XIENCE V'M (Abbott Vascular, Santa Clara, CA, USA). Endeavor Sprint, Endeavor Resolute, and Xience $V$ stents were provided by the manufacturer, while Taxus Liberté stents were obtained from our own stock (all companies had been invited to provide stents). Stent dimensions were: for Xience $\mathrm{V}, 3.5 \times 23 \mathrm{~mm}$ $(n=3)$; for Endeavor Resolute, $3.5 \times 24 \mathrm{~mm}(\mathrm{n}=3)$; for Endeavor Sprint, $3.5 \times 24 \mathrm{~mm}(\mathrm{n}=3)$; and for Taxus Liberté, $3.5 \times 28 \mathrm{~mm}(\mathrm{n}=1)$ and $3.5 / 8 \mathrm{~mm}(\mathrm{n}=2)$.

Taxus Liberté consists of the Liberté ${ }^{T M}$ stainless steel platform (Figure $1 \mathrm{~A}$ ) with a strut thickness of $97 \mu \mathrm{m}$ covered by a $17.8 \mu \mathrm{m}$ thick coating consisting of SIBS (styrene-b-isobutylene-b-styrene) polymer and paclitaxel. ${ }^{14}$ Endeavor Sprint consists of the cobaltchromium DriverTM platform (Figure 1B) with a strut thickness of $91 \mu \mathrm{m}$, covered by a $4.8 \mu \mathrm{m}$ thick coating of phosphorylcholine (10\%) and Zotarolimus (90\%). ${ }^{15}$ Endeavor Resolute is also based on the Driver ${ }^{\mathrm{TM}}$ platform with Zotarolimus as the antiproliferative drug, while the coating consists of drug plus Biolinx ${ }^{\mathrm{TM}}$ polymer; ${ }^{16}$ the coating thickness is $5.6 \mu \mathrm{m}$ (information by manufacturer, personal communication). Xience $\mathrm{V}$ stents consist of the Vision ${ }^{\mathrm{TM}}$ cobalt-chromium platform (Figure 1C) with a strut thickness of $81 \mu \mathrm{m}$, covered by a $7.8 \mu \mathrm{m}$ thick layer of a mixture of fluoropolymer and Everoliums as the antiproliferative drug. ${ }^{17}$

\section{DES expansion protocol}

All stents (sterile packed; within expiration date) were expanded by an interventional cardiologist under sterile conditions in a sterile
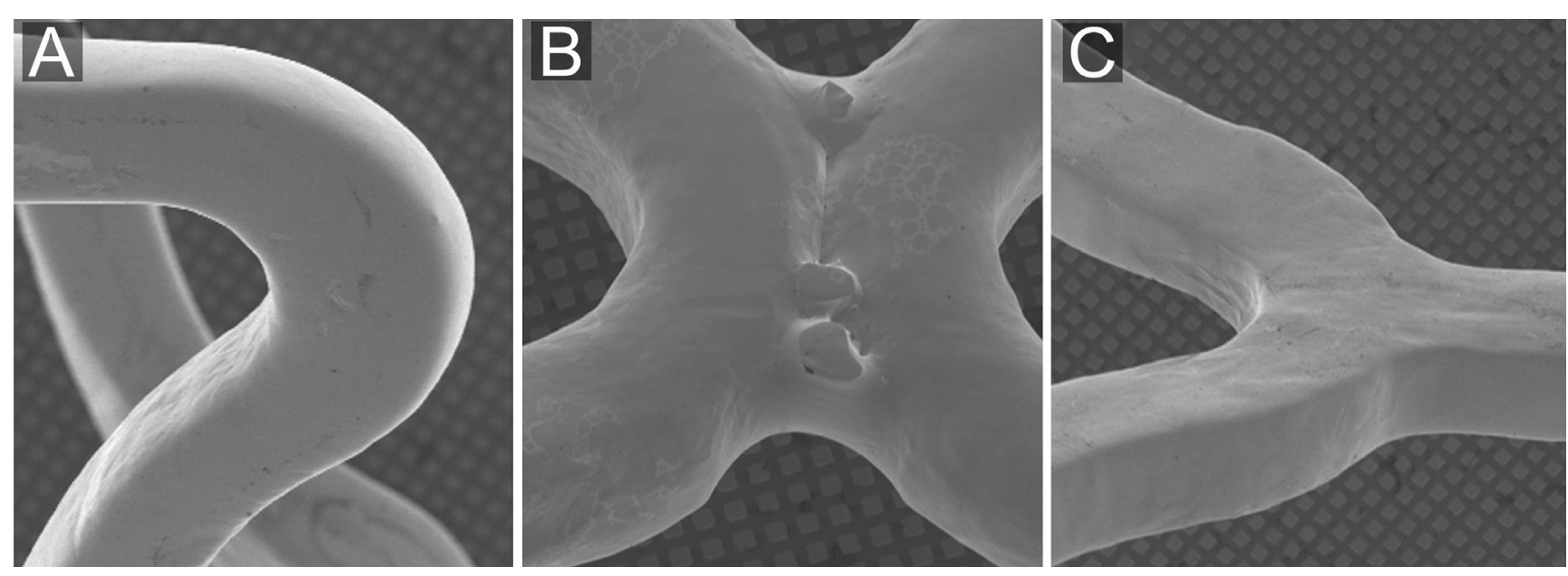

Figure 1. Scanning electron microscopic appearance of bare metal stents. The SEM-images demonstrate, in general, a relatively smooth surface (all three stents) as well as some irregularities at welding points (Driver stent only): A) Liberté stent (bare metal platform of Taxus Liberté); B) Driver stent (bare metal platform of Endeavor sprint and Endeavor Resolute); C) Vision stent (bare metal platform of Xience V). 
water bath at $37^{\circ} \mathrm{C}$. Balloon expansion of the DES was performed at $14 \mathrm{~atm}$, and all DES were consecutively dried under laminar air flow at room temperature. Stent expansion, drying, and examination of the samples were performed at the University of Twente in Enschede at an experimental laboratory with laminar air flow, being almost free from dust.

\section{Light microscopy}

The surface of one stent per DES type was examined by stereoscopic light microscopy (Zeiss Axiovert 200 inverted microscope) at 50- to 200-fold magnifications in an exploratory fashion to search for irregularities and/or defects. Digital images were taken where appropriate in order to portray typical irregularities.

\section{Scanning electron microscopic analysis}

SEM imaging was performed with a Phillips XL30/ESEM FEG scanning electron microscope ( $\mu$ Candela Systems). In order to see the coating as pure as possible, all DES remained untreated (i.e., no gold layer was sprayed on DES). A $1 \mathrm{KeV}$-protocol was applied (average working distance $10 \mathrm{~mm}$; range 6-12 mm sample dependent).

Exploratory assessment. First, one sample per DES type was examined with SEM at 50- to 60-fold magnification to detect and locate suspected irregularities.

Defining and classifying coating irregularities. Areas of coating irregularities as detected in the previous step were further examined at 200 to 500-fold magnification to characterise them and to distinguish them from artifacts. This information was used to develop a classification of coating irregularities. In addition, by zooming in on individual irregularities, the analysts learned to discriminate various types of irregularities at a lower magnification level. This was a prerequisite for measuring the incidence of individual coating irregularities.

Measurement incidence of coating irregularities. Finally, the DES surface was thoroughly scanned at 50-to-70-fold magnifications on eight stents (two of each type); care was taken to avoid overlap between scanned areas. A total of 360 SEM images (including both, luminal and abluminal aspect) were carefully examined to determine the incidence of all prespecified coating irregularities on different DES types. Despite some difference in stent length, the actual stent surface area examined by SEM for quantification of coating irregularities was identical in all four DES types. Data are presented as frequency of each irregularity per image field at 60-fold magnification. If individual magnifications differed slightly from this level, a correction factor was applied to normalise findings for 60-fold magnification. In addition, the dimensions of coating irregularities were measured (length $x$ width; diameter for defects with a round appearance). In Endeavor Sprint stents (typically on the luminal aspect), bare metal zones were generally too large to permit a meaningful quantification.

\section{Statistics}

Data are presented as a mean \pm one standard deviation. The incidence of various DES irregularities in the four DES types was compared by using the Kruskal-Wallis test. In cases in which the Kruskal-Wallis test demonstrated a significant difference, a MannWhitney test was performed between each two samples. P-values $<0.05$ were considered significant; the level of significance for the Mann-Whitney test was adjusted by Bonferroni-correction. Statistical analyses were performed with the software of SPSS version 15.0 (SPSS Inc., Chicago, IL, USA).

\section{Results}

\section{Exploratory light microscopy}

On all DES types, light microscopy detected coating irregularities (Figure 2).

\section{SEM exploration and categorisation of irregularities}

Using 200-to-500-fold magnifications, we detected and characterised 14 types of coating irregularities. These irregularities were classified into four categories: (I) reduced thickness; (II) increased thickness; (III) inhomogeneous distribution; and (IV) displacement of coating; definitions are presented in Table 1. Examples are given in Figures 3 and 4.

Table 1. Classification of irregularities of durable polymer-based DES coatings.

\section{Categories}

I. Irregularities with reduced thickness of coating

II. Irregularities with increased thickness of coating

III. Irregularities with inhomogeneous coating

IV. Irregularities with displacement of coating

\section{Types (within individual categories); Figure=typical example}

IA. Small or big areas with aspect of bare metal, not fulfilling criteria of IB or IC (see below); Fig. 3A and 3B

IB. Cracks, i.e. sharp-edged coating irregularity extending from the surface deep into the coating, sometimes with exposure of underlying stent/primer; Fig. $3 \mathrm{C}$

IC. Reduced thickness of DES coating at strut crossings; Fig. 3D

IIA. "Auricle-shaped" excess of coating; Fig. 3E

IIB. Ridge-shaped excess of coating connecting two facets of a strut; Fig. 1F

IIC. Small rounded structure of excess coating; Fig. $3 \mathrm{G}$

IIIA. Crater-shaped irregularity with metal exposure, i.e., circular or elliptical irregularity with centrally reduced thickness of coating (including bare metal areas) and increased thickness of coating at the peripheral zone; Fig. $3 \mathrm{H}$

IIIB. Crater-shaped irregularity without metal exposure, i.e., circular or elliptical irregularity with centrally reduced thickness of coating and increased thickness of coating at the peripheral zone; Fig. $4 \mathrm{~A}$ and $2 \mathrm{~B}$

IIIC. Small crater-shaped irregularity, i.e., irregularity with appearance of punched-out hole. (bottom not visible; Fig. 4C)

IIID. Wrinkles, i.e., shallow minimal linear irregularities; Fig. 4D

IIIE. Flattened coating enclosed between two linear thickenings of coating material; Fig. 4E

IVA. Webbing with metal exposure; Fig. 4F

IVB. Webbing without metal exposure; Fig. $4 \mathrm{G}$

IVC. Fragments of coating, i.e., mostly detached piece of coating which keeps loosely attached to the main coating; Fig. $4 \mathrm{H}$ 


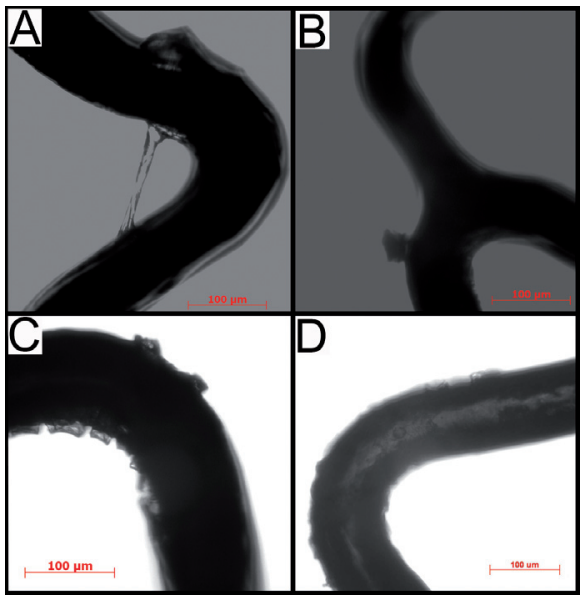

Figure 2. Light microscopic imaging of drug-eluting stents. A) Example of webbing in a Taxus Liberté. B) Fragment of coating on a Xience V. C) Cracks and crater irregularities on an Endeavor Resolute. D) Heterogeneity of coating of an Endeavor Sprint.
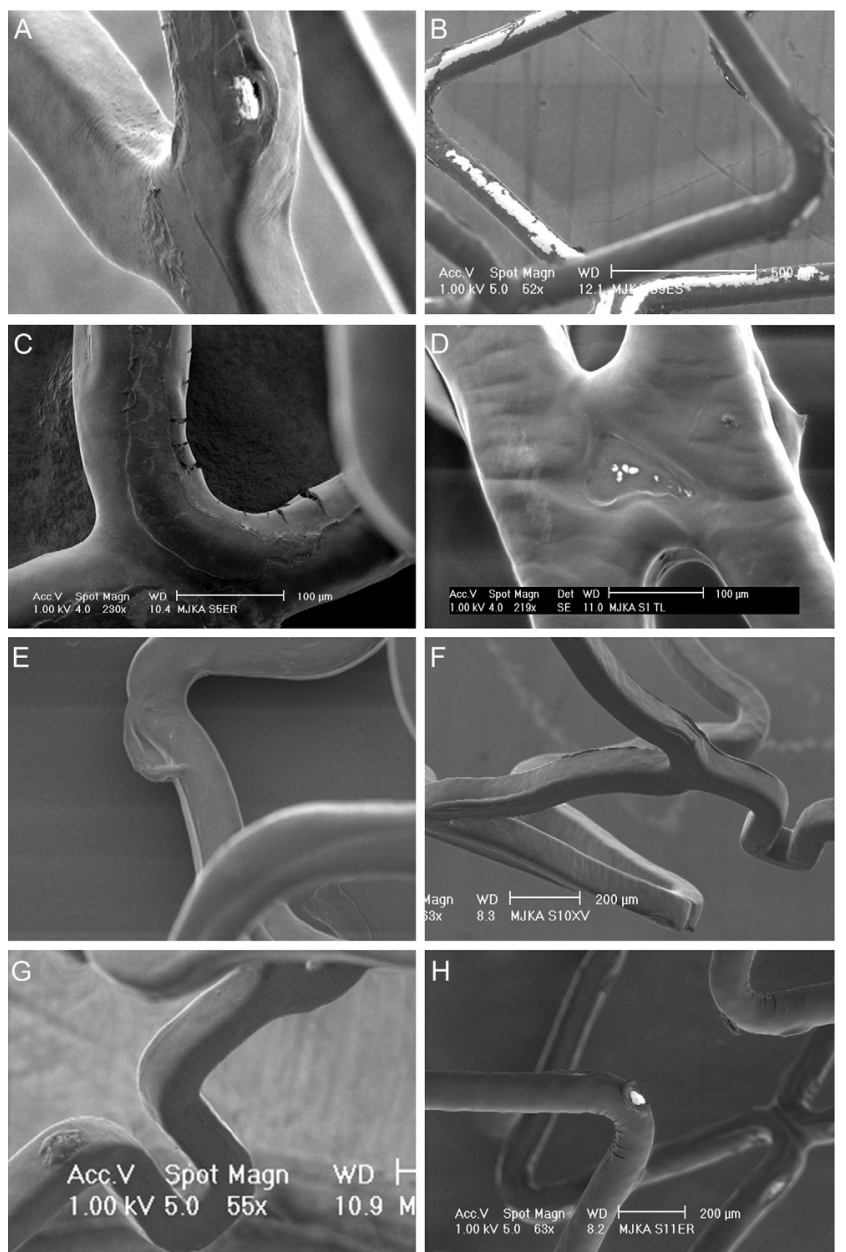

Figure 3. Scanning electron microscopic appearance of coating irregularities (part 1). A) An apparently bare-metal area on Xience V. B) An Endeavor Sprint with a visual aspect of bare-metal areas. C) Cracks in the coating of an Endeavor Resolute. D) Thinning of the coating on a crosslink of a Taxus Liberté. E) "Auricle-shaped" excess of coating on a Taxus Liberté. F) Ridge-like excess of coating on a Xience V. G) Small round structure of excess coating on a Xience $V$. H) Crater irregularity with an apparent central bare-metal area on an Endeavor Resolute.
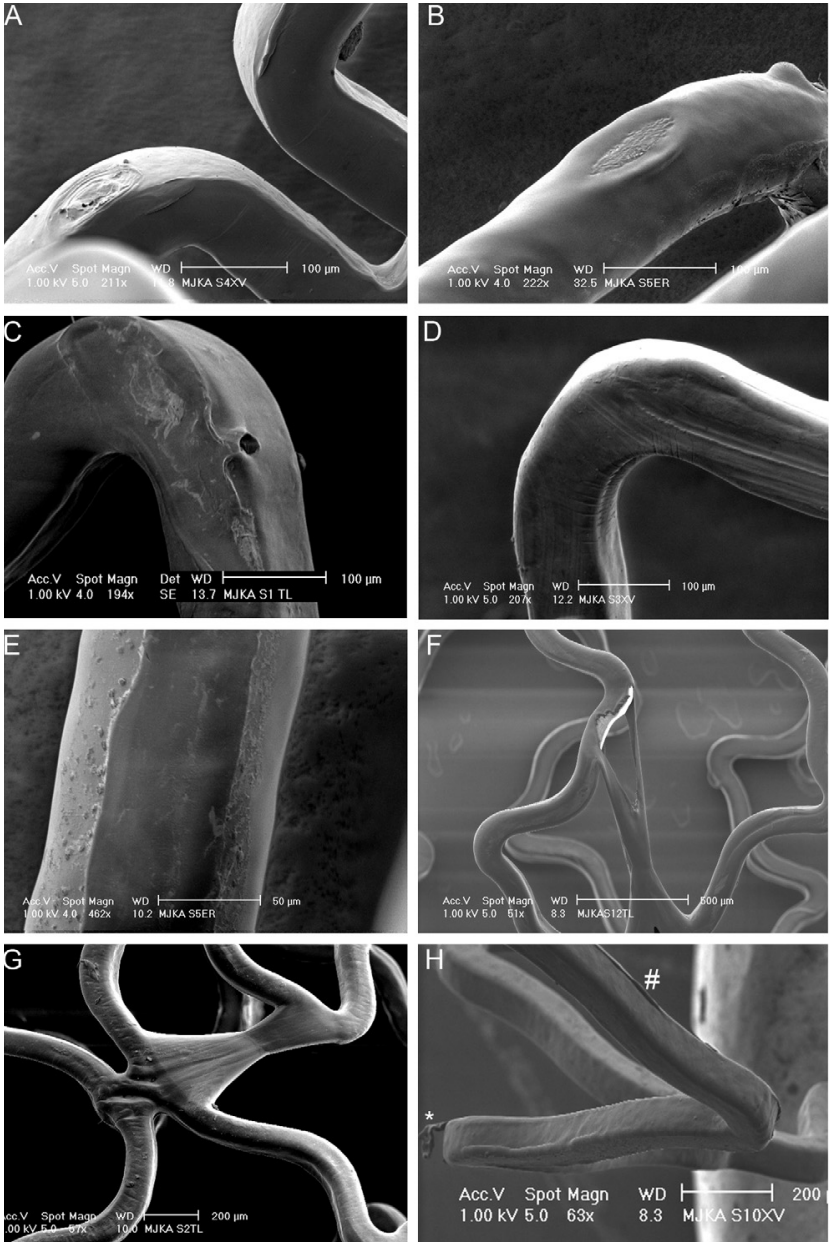

Figure 4. Scanning electron microscopic appearance of coating irregularities (part 2). A) Crater-shaped irregularity without bare-metal exposure on a Xience $V$. B) Crater-shaped irregularity without bare-metal exposure on an Endeavor Resolute. C) Small crater-shaped irregularity on a Taxus Liberté. D) Wrinkles on a Xience V. E) Flattened coating on luminal surface of an Endeavor Resolute. F) Webbing with bare-metal exposure on a Taxus Liberté. G) Webbing without bare-metal exposure on a Taxus Liberté. $H$ ) Detached fragment of coating (*) and ridge-like thickening of coating (\#) on a Xience $V$.

\section{Quantification of irregularities}

For each of the four DES types, we systematically analysed 90 nonoverlapping images at 50-to-70-fold magnification (45 images of luminal and 45 of abluminal aspect). The total incidence of irregularities differed among DES types $(p<0.0001$; on average $6.6 \pm 4.2 / S E M$ image at 60-fold magnification). The incidence of different irregularities is presented in Tables 2-5. On all four DES types, there were areas with visual aspects of bare metal; but incidence, shape, and size of these areas differed largely among the DES types (Table 2). Increased thickness of coating was seen in Taxus Liberté and - to a smaller extent - in Xience $V$ stents ( $p=0.0001$; Table 3).

Cracks of the coating were found in Endeavor Sprint and Resolute (Table 2), while wrinkles were only seen in Taxus Liberté and in 
Table 2. Category I DES coating irregularities (reduced thickness; frequencies and dimensions).

\begin{tabular}{|c|c|c|c|c|c|c|c|c|c|c|c|c|c|c|}
\hline \multirow[t]{2}{*}{ Types } & \multirow[b]{2}{*}{ Aspect } & & \multicolumn{3}{|c|}{ Taxus Liberté } & \multicolumn{3}{|c|}{ Endeavor Sprint } & \multicolumn{3}{|c|}{ Endeavor Resolute } & \multicolumn{3}{|c|}{ Xience V } \\
\hline & & & Luminal & Abluminal & Total & Luminal & Abluminal & Total & Luminal & Abluminal & Total & Luminal & Abluminal & Total \\
\hline \multirow{5}{*}{$\begin{array}{l}\text { IA) Small or big areas } \\
\text { of bare metal not } \\
\text { fulfilling criteria } \\
\text { for IB of IC. } \\
\ddagger, \#, \S, \bullet\end{array}$} & \multirow{5}{*}{$\begin{array}{l}\text { Mean frequency } \\
\text { of irregularity } \\
\text { per SEM field at } \\
60 \text {-fold } \\
\text { magnification } \\
\text { Dimensions }\end{array}$} & \multirow{5}{*}{$\begin{array}{l}\text { Small } \\
\text { areas } \\
\text { Big } \\
\text { areas }\end{array}$} & 0.58 & 0.32 & 0.45 & 0.12 & 3.96 & 2.04 & 1.19 & 1.79 & 1.49 & 0.04 & 0.28 & 0.16 \\
\hline & & & \pm 0.75 & \pm 0.58 & \pm 0.68 & \pm 0.47 & \pm 1.91 & \pm 2.37 & \pm 1.06 & \pm 1.7 & \pm 1.43 & \pm 0.21 & \pm 0.7 & \pm 0.52 \\
\hline & & & 0 & 0 & 0 & 2.49 & 0.86 & 1.67 & 0 & 0 & 0 & 0 & 0 & 0 \\
\hline & & & & & & \pm 1.09 & \pm 0.93 & \pm 1.3 & & & & & & \\
\hline & & & \multicolumn{3}{|c|}{$135 \pm 66 \times 46 \pm 19 \mu \mathrm{m}$} & \multicolumn{3}{|c|}{$\begin{array}{l}\text { Very large areas, } \\
\text { too large to be measured }\end{array}$} & \multicolumn{3}{|c|}{$81 \pm 24 \times 36 \pm 3 \mu \mathrm{m}$} & \multicolumn{3}{|c|}{$57 \pm 25 \times 24 \pm 9 \mu \mathrm{m}$} \\
\hline \multirow[t]{2}{*}{$\begin{array}{l}\text { IB) Cracks } \\
{ }^{*}, \dagger, \ddagger, \Phi, \#, \|\end{array}$} & \multirow{2}{*}{\multicolumn{2}{|c|}{$\begin{array}{l}\text { Mean frequency } \\
\text { /field } \\
\text { Dimensions }\end{array}$}} & 0 & 0 & 0 & $\begin{array}{c}2.34 \\
\pm 0.98\end{array}$ & $\begin{array}{r}2.91 \\
\pm 1.15\end{array}$ & $\begin{array}{l}2.62 \\
\pm 1.1\end{array}$ & $\begin{array}{c}3.23 \\
\pm 0.78\end{array}$ & $\begin{array}{r}4.02 \\
\pm 1.27\end{array}$ & $\begin{array}{c}3.63 \\
\pm 1.12\end{array}$ & 0 & 0 & 0 \\
\hline & & & & & & \multicolumn{3}{|c|}{$57 \pm 23 \times 6 \pm 3 \mu \mathrm{m}$} & \multicolumn{3}{|c|}{$52 \pm 19 \times 5 \pm 3 \mu \mathrm{m}$} & & & \\
\hline \multirow{2}{*}{$\begin{array}{l}\text { IC) Reduced coating } \\
\text { at strut crossing } \\
*, \dagger, \downarrow, \S\end{array}$} & Mean frequency & & 0.38 & 0.51 & 0.44 & 0 & 0 & 0 & 0 & 0 & 0 & 0 & 0 & 0 \\
\hline & $\begin{array}{l}\text { /field } \\
\text { Dimensions }\end{array}$ & & \multicolumn{3}{|c|}{$177 \pm 38 \times 83 \pm 58 \mu \mathrm{m}$} & & & & & & & & & \\
\hline
\end{tabular}

Differences in incidence of irregularities: *difference among the stents: $p<0.05 ; \nmid$ Taxus Liberté vs. Endeavor Sprint: $p<0.0125$ (Bonferroni); $\ddagger$ Taxus Liberté vs. Endeavor Resolute: $p<0.0125$ (Bonferroni); §Taxus Liberté vs. Xience V: $p<0.0125$ (Bonferroni); ||Endeavor Sprint vs. Endeavor Resolute: $p<0.0125$ (Bonferroni); qIEndeavor Sprint vs. Xience V: $p<0.0125$ (Bonferroni); \#Endeavor Resolute vs. Xience V: $p<0.0125$ (Bonferroni); • As the large size of type IA lesions in Endeavor Sprint stents prevented reliable quantification, this stent was excluded from direct comparison with the other DES types (this accounts for type IA lesions only).

Table 3. Category II DES coating irregularities (increased thickness; frequencies and dimensions).

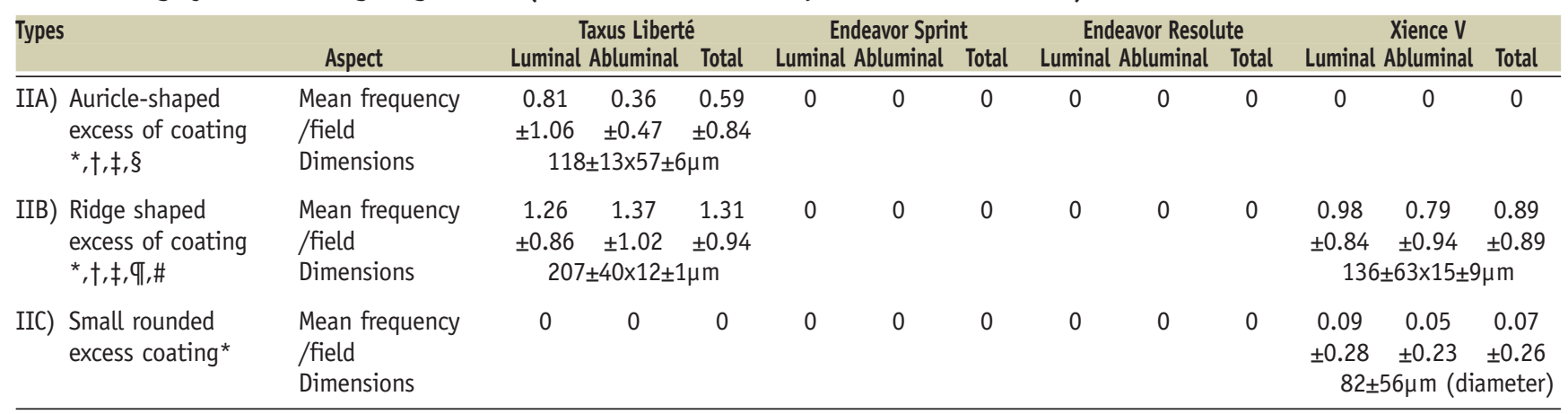

Differences in incidence of irregularities: *difference among the stents: $p<0.05 ; \nmid$ Taxus Liberté vs. Endeavor Sprint: $p<0.0125$ (Bonferroni); $\ddagger$ Taxus Liberté vs. Endeavor Resolute: $p<0.0125$ (Bonferroni); §Taxus Liberté vs. Xience V: $p<0.0125$ (Bonferroni); ||Endeavor Sprint vs. Endeavor Resolute: $p<0.0125$ (Bonferroni); qIEndeavor Sprint vs. Xience V: $p<0.0125$ (Bonferroni); \#Endeavor Resolute vs. Xience V: $p<0.0125$ (Bonferroni); • As the large size of type IA lesions in Endeavor Sprint stents prevented reliable quantification, this stent was excluded from direct comparison with the other DES types (this accounts for type IA lesions only).

Xience $V(p<0.0001 ;$ Table 4$)$. Inhomogeneous distribution of coating was found on each DES type, but incidence and size differed between DES types (Table 4). Displacement of coating was observed mainly in Taxus Liberté and Xience $\mathrm{V}$ - and to a much lower extent in Endeavor Resolute (Table 5).

The size of the various irregularities differed (Tables 2-5). Visual assessment revealed that areas with bare metal aspects were largest on Endeavor Sprint (too large to permit meaningful measurement, as previously mentioned). On Xience $V$, the incidence of areas with bare metal aspects was particularly low and their dimensions were relatively small.

Certain irregularities were found on constant locations of specific DES types, forming typical patterns of irregularities for these DES types. Cracks were generally found on the inner curvatures of crowns (curved struts), where they could be observed on both, the luminal and abluminal aspect of stents. Crater lesions were mainly detected at the apex on the outer curvature of a loop and at sites, where struts of unexpanded, crimped stents may have been in contact with each other.

\section{Discussion}

\section{Main findings}

Examination of the four commercially available types of DES demonstrated a wide range of 14 types of irregularities that were classified into four categories according to amount and homogeneity of coating. The different DES types showed certain irregularities at constant locations, forming typical patterns in panoramic SEM images. The total incidence of irregularities differed largely among DES types. All DES types showed stent areas with an aspect of bare metal; however, incidence, shape, and size differed among stent types with the largest areas being found in Endeavor Sprint. Cracks were found in Endeavor Sprint and Resolute only, while wrinkles were exclusively seen in Taxus Liberté and Xience V. Inhomogeneous distribution of coating was found on each DES type, but the incidence differed between types and was least in the Taxus Liberté, which - on the other hand - was the only DES type that showed webbing associated with large bare-metal exposure. 
Table 4. Category III DES coating irregularities (inhomogeneous thickness; frequencies and dimensions).

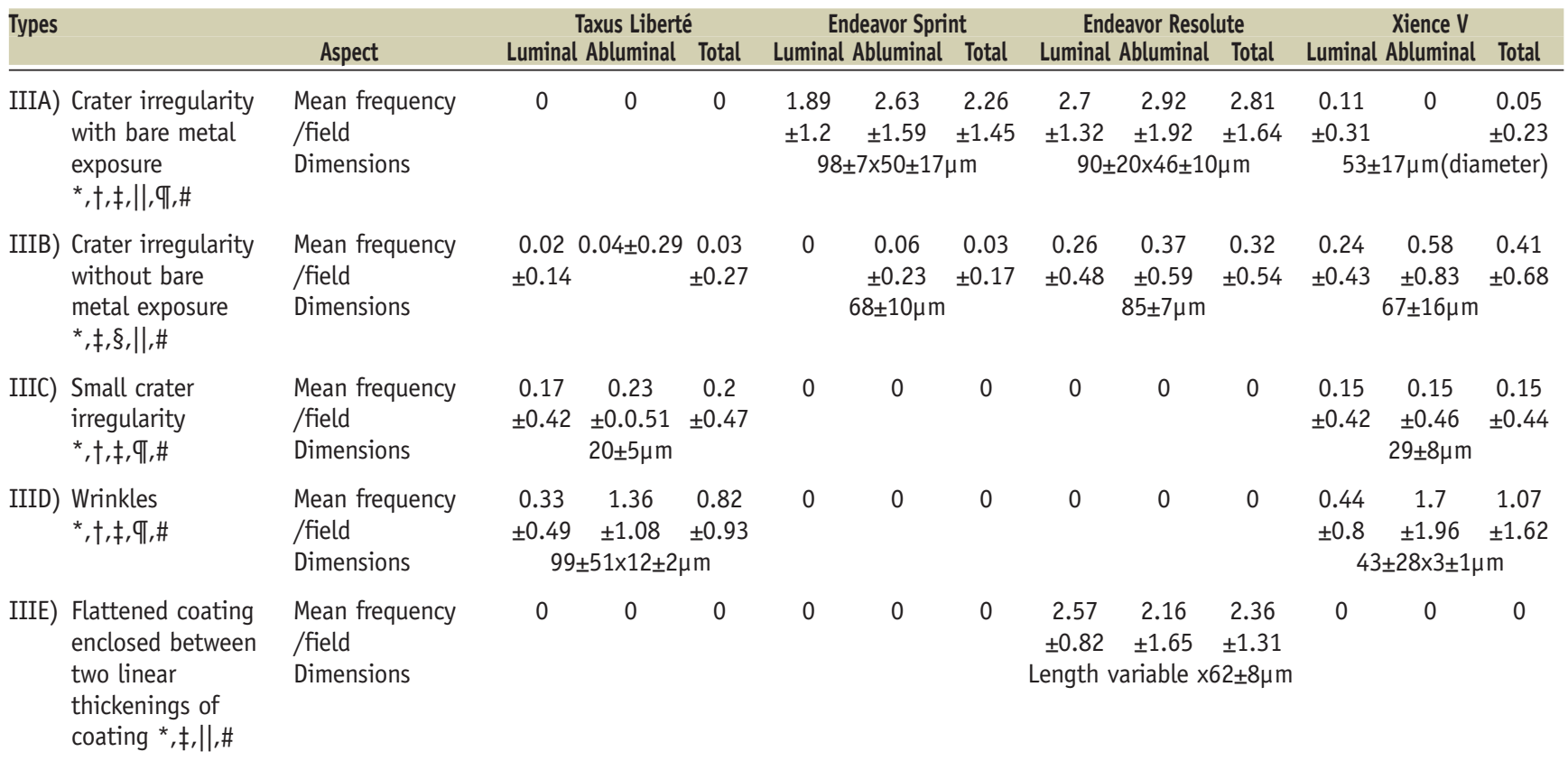

Differences in incidence of irregularities: *difference among the stents: $p<0.05 ; \nmid$ Taxus Liberté vs. Endeavor Sprint: $p<0.0125$ (Bonferroni); $\ddagger$ Taxus Liberté vs. Endeavor Resolute: $p<0.0125$ (Bonferroni); §Taxus Liberté vs. Xience V: $p<0.0125$ (Bonferroni); ||Endeavor Sprint vs. Endeavor Resolute: $p<0.0125$ (Bonferroni); qाEndeavor Sprint vs. Xience V: $p<0.0125$ (Bonferroni); \#Endeavor Resolute vs. Xience V: $p<0.0125$ (Bonferroni); • As the large size of type IA lesions in Endeavor Sprint stents prevented reliable quantification, this stent was excluded from direct comparison with the other DES types (this accounts for type IA lesions only).

Table 5. Category IV DES coating irregularities (displacement; frequencies and dimensions).

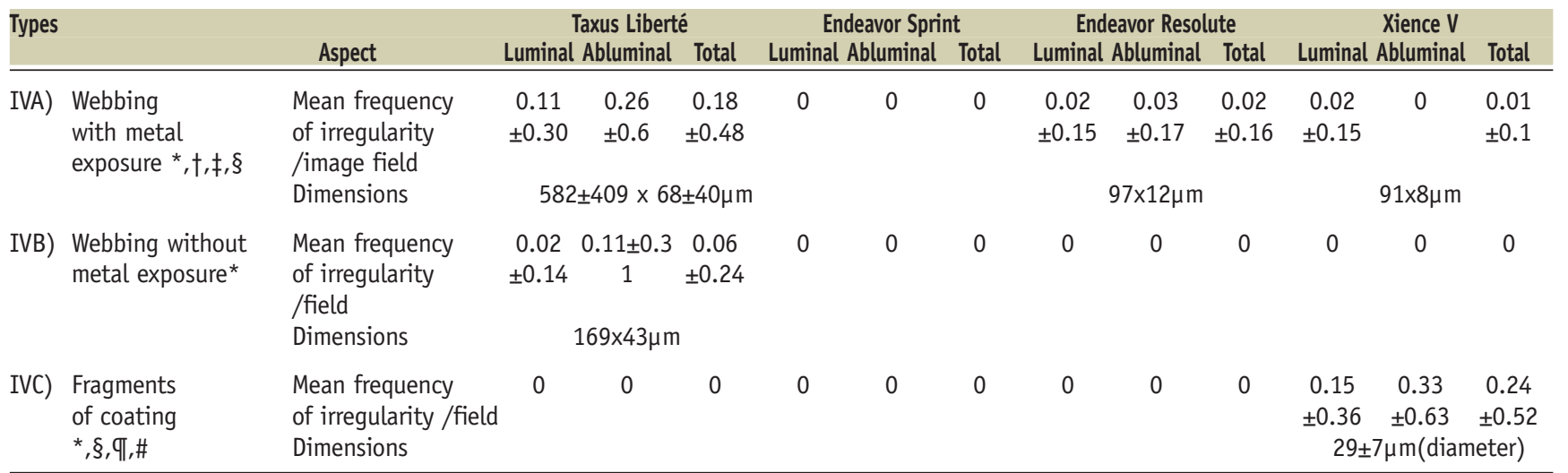

Differences in incidence of irregularities: * difference among the stents: $p<0.05 ; \nmid$ Taxus Liberté vs. Endeavor Sprint: $p<0.0125$ (Bonferroni); $\ddagger$ Taxus Liberté vs. Endeavor Resolute: $p<0.0125$ (Bonferroni); §Taxus Liberté vs. Xience V: $p<0.0125$ (Bonferroni); ||Endeavor Sprint vs. Endeavor Resolute: $p<0.0125$ (Bonferroni); qIEndeavor Sprint vs. Xience V: $p<0.0125$ (Bonferroni); \#Endeavor Resolute vs. Xience V: $p<0.0125$ (Bonferroni); • As the large size of type IA lesions in Endeavor Sprint stents prevented reliable quantification, this stent was excluded from direct comparison with the other DES types (this accounts for type IA lesions only).

\section{Rationale of the study}

Recent clinical studies suggested potential differences between DES-types in their capability to prevent restenosis. In addition, late and very late stent thrombosis continue to be important challenges. Late or incomplete endothelialisation of DES increases the risk of stent thrombosis, most likely as a result of prolonged contact between blood and DES. ${ }^{18}$

The surface texture, as well as imperfections of the distribution of the polymer, may have implications with regards to safety and efficacy. While a mild degree of roughness of the surface of endovascular implants may promote endothelialisation (versus perfectly smooth surfaces), ${ }^{19}$ irregular and rough surface textures increase thrombogenicity. ${ }^{20}$ Furthermore, on polymer-based DES, a reduction in polymer thickness or the focal absence of polymer, may reduce the local, drug-induced inhibition of neointimal proliferation. Therefore, in the present study, we assessed the surface of four types of DES with SEM to document and quantify all forms of coating irregularities. 


\section{Choice of DES examined}

There is a development of polymer coating through DES generations, aiming at optimisation of biocompatibility and release profile. ${ }^{21}$ In this study, we examined DES of different generations which all share the presence of the durable-polymer component. We have clinical experience with the use of all four DES. According to a recent consensus for preclinical evaluation of DES, ${ }^{22}$ we examined three stents per DES type.

\section{Microscopic examination of DES coating}

The two-dimensional character of light microscopic images substantially limited the visualisation of some coating irregularities, and was less suitable for quantification of (subtle) irregularities. Therefore, we used SEM to verify, categorise, and quantify the irregularities. Only very few SEM-data on DES coating irregularities have been published so far. Otsuka et al used SEM to describe polymer irregularities on first-generation DES. ${ }^{13}$ The authors observed webbing in Taxus Express stents, however, they reported no quantitative information on incidence and size of this and other polymer irregularities. Ormiston et al presented data on both SEM and environmental SEM examination of some DES, including Taxus Express and Enveavor (Sprint) stents with phosphorylcholine-based coatings. ${ }^{23}$ Some of the irregularities quantified in our study, such as webbing and crater irregularities, are consistent with the findings of Ormiston and coworkers. The United States Food and Drug Administration (FDA) recently reported the presence of microcracks in the drug-polymer layer and areas of (apparent) coating loss in Phosphorylcholine-based Endeavor (Sprint) stents. ${ }^{24}$ This information is consistent with our findings.

\section{Elasticity of coating and irregularity formation}

The geometry of the stent platform, details of the process of coating stent, and both composition and physical characteristics of the coating (e.g., elasticity), may contribute to the reproducible shape and location of certain irregularities. DES expansion stretches the coating. This may lead to wrinkles if the elasticity of coating is high (Taxus Liberté, Xience V), while it may lead to cracks if the elasticity is low (Endeavor Sprint and Resolute). In line with this is the fact that adhesion of the polymer coating on adjacent stent struts (socalled webbing) was mainly seen in Taxus Liberté, while Endeavor Sprint, Endeavor Resolute, and (to a lower extent) Xience $V$ showed the so-called crater lesion, which is presumably equivalent to webbing in DES with less elastic coatings.

\section{Implications}

The present in vitro data should be interpreted cautiously, as the value of DES should be primarily judged based on clinical data. Nevertheless, in vitro data may sometimes help to find explanations for differences in clinical outcome or surrogate endpoints by coronary angiography, intravascular ultrasound, or optical coherence tomography.

The local antiproliferative potential of DES may be reduced at sites of major polymer loss, particularly at bare metal areas. We found a relatively large size of such irregularities in Endeavor Sprint stents, which could be related to the somewhat higher restenosis rate of this stent as compared to the Cypher stent (Cordis Corporation, Miami Lakes, FL, USA); ${ }^{25}$ nevertheless, the restenosis rate of this stent was significantly lower than that of BMS. ${ }^{26}$

The size of polymer irregularities was for the most part smaller on the more recently introduced DES types (Endeavor Resolute, Xience V) as compared to earlier DES types (Endeavor Sprint, Taxus Liberté). Irregularities with inhomogeneous or displaced polymer coating increase roughness of DES, and thus thrombogenicity. In addition, detachment of coating material could be a source of microembolism; this risk may be insignificant as durable-polymer based DES were previously associated neither with increased periprocedural cardiac marker release nor with increased inhospital major events. 2,25,27,28 Nevertheless, Virmani et al showed that hypersensitivity reaction to durable polymer fragments can play a role in the process of late and very late in-DES thrombus formation, ${ }^{29}$ a problem which may be partly solved by biodegradable coatings or biodegradable stents / DES..$^{21,30-33}$

\section{Limitations}

As an inherent limitation of bench-side studies, the present in vitro study does not exactly mimic the conditions in vivo. Even DES, with somewhat less favourable SEM appearance, may be clinically highly efficacious and safe. For example, a higher biocompatibility of certain DES coatings may compensate for a somewhat higher incidence of certain irregularities on these coatings. Therefore, clinical data are most important to form a prudent opinion of a DES. Nevertheless, we feel that a meticulous SEM examination of the DES surface (including quantitative assessment) is important because it adds valuable information to the overall picture of a DES, and may sometimes help to understand clinical data. During stent delivery (in clinical practice), potential shear between the (abluminal) DES surface and the vessel wall may lead to additional defects that could vary depending on characteristics of target lesion and vessel (e.g., vessel tortuosity; calcification; lesion location) and characteristics of DES (e.g., stent platform; coating). Nevertheless, the assessment of this complex issue is beyond the scope of the present in vitro study. In our experimental set-up, we did not implant stents in vessels or vascular phantoms; implantation in vessels or vascular phantoms might have reduced some irregularities. However, our current experimental approach avoided any additional defect that could have resulted from scratching the DES along (calcified) vessel walls, or from regaining DES out of vascular phantoms or specimens. Our data were obtained in DES with a nominal diameter of $3.5 \mathrm{~mm}$; findings may be somewhat different in small DES, e.g. in DES with a diameter of 2.25 or $2.5 \mathrm{~mm}$.

Expansion in water followed by drying could theoretically have affected the more hydrophilic DES coatings (e.g., aggravate some coating irregularities). The use of environmental SEM may avoid this problem, however, in comparing images obtained in our SEM study with illustrations of studies with environmental SEM in corresponding DES, ${ }^{23}$ we found identical irregularities, with a very similar severity. However, due to technical issues, environmental SEM may be less suitable for quantitative studies such as the present study. 


\section{Conclusions}

Scanning electron microscopic assessment of the incidence and size of irregularities in the drug-eluting coating of four types of commercially available DES demonstrated significant differences between DES types. Our data may be considered in the ongoing discussion on differences between DES and could serve as reference to compare novel DES.

\section{Acknowledgements}

We are very grateful to Jan Feijen, MSc PhD, Professor in Biomaterials and Polymer Chemistry and Scientific Director of the Institute for Biomedical Technology (BMTI) at the University of Twente in Enschede for his valuable suggestions as well as for proofreading the current manuscript. While free DES samples were provided by Abbott Vascular and Medtronic Inc., no financial support was obtained; the study was investigator-initiated.

\section{References}

1. Colombo A, Drzewiecki J, Banning A, Grube E, Hauptmann K, Silber S, Dudek D, Fort S, Schiele F, Zmudka K, Guagliumi G, Russell ME; TAXUS II Study Group.Randomized study to assess the effectiveness of slow- and moderate-release polymer-based paclitaxel-eluting stents for coronary artery lesions. Circulation 2003;108:788-94.

2. Moses JW, Leon MB, Popma JJ, Fitzgerald PJ, Holmes DR, O'Shaughnessy C, Caputo RP, Kereiakes DJ, Williams DO, Teirstein PS, Jaeger JL, Kuntz RE; SIRIUS Investigators. Sirolimus-eluting stents versus standard stents in patients with stenosis in a native coronary artery. $N$ Engl J Med 2003;349:1315-23.

3. Serruys PW, Degertekin M, Tanabe K, Abizaid A, Sousa JE, Colombo A, Guagliumi G, Wijns W, Lindeboom WK, Ligthart J, de Feyter PJ, Morice MC; RAVEL Study Group. Intravascular ultrasound findings in the multicenter, randomized, double-blind RAVEL trial. Circulation 2002;106:798-803.

4. von Birgelen C, Erbel R. The stent is here to stay: a note on stenting, ultrasound imaging, and the prevention of restenosis. Eur Heart $J$ 2002;23:595-7.

5. Stettler C, Wandel S, Allemann S, Kastrati A, Morice MC, Schömig A, Pfisterer ME, Stone GW, Leon MB, de Lezo JS, Goy JJ, Park SJ, Sabaté M, Suttorp MJ, Kelbaek H, Spaulding C, Menichelli M, Vermeersch P, Dirksen MT, Cervinka P, Petronio AS, Nordmann AJ, Diem P, Meier B, Zwahlen M, Reichenbach S, Trelle S, Windecker S, Jüni P. Outcomes associated with drug-eluting and bare-metal stents: a collaborative network meta-analysis. Lancet 2007;370:937-48.

6. Spaulding C, Daemen J, Boersma E, Cutlip DE, Serruys PW. A pooled analysis of data comparing sirolimus-eluting stents with baremetal stents. N Engl J Med 2007;356:989-97.

7. Schömig A, Dibra A, Windecker S, Mehilli J, Suárez de Lezo J, Kaiser C, Park SJ, Goy JJ, Lee JH, Di Lorenzo E, Wu J, Jüni P, Pfisterer ME, Meier B, Kastrati A. A meta-analysis of 16 randomized trials of sirolimuseluting stents versus paclitaxel-eluting stents in patients with coronary artery disease. J Am Coll Cardiol 2007;50:1373-80.

8. Kastrati A, Mehilli J, Pache J, Kaiser C, Valgimigli M, Kelbaek H, Menichelli M, Sabaté M, Suttorp MJ, Baumgart D, Seyfarth M, Pfisterer ME, Schömig A. Analysis of 14 trials comparing sirolimus-eluting stents with bare-metal stents. N Engl J Med 2007;356:1030-9.
9. Daemen J, Wenaweser P, Tsuchida K, Abrecht L, Vaina S, Morger C, Kukreja N, Jüni $P$, Sianos G, Hellige G, van Domburg RT, Hess OM, Boersma E, Meier B, Windecker S, Serruys PW. Early and late coronary stent thrombosis of sirolimus-eluting and paclitaxel-eluting stents in routine clinical practice: data from a large two-institutional cohort study. Lancet 2007;369:667-78.

10. Wenaweser $P$, Daemen J, Zwahlen $M$, van Domburg R, Jüni $P$, Vaina S, Hellige G, Tsuchida K, Morger C, Boersma E, Kukreja N, Meier B, Serruys PW, Windecker S. Incidence and correlates of drug-eluting stent thrombosis in routine clinical practice. 4-year results from a large 2-institutional cohort study. J Am Coll Cardiol 2008;52:1134-40.

11. Mani G, Feldman MD, Patel D, Agrawal CM. Coronary stents: a materials perspective. Biomaterials 2007;28:1689-710.

12. Ormiston J, Webster $M$, Ruygrok $P$, et al. Polymer integrity after Cypher and Taxus stent implantation: A scanning electron microscope study. http://www.tctmd.com.

13. Otsuka Y, Chronos NA, Apkarian RP, Robinson KA. Scanning electron microscopic analysis of defects in polymer coatings of three commercially available stents: comparison of BiodivYsio, Taxus and Cypher stents. J Invasive Cardiol 2007; 19:71-6.

14. FDA Summary of Safety and Effectiveness Data of Taxus Liberté. P060008. 10-10-2008. http://www.fda.gov/cdrh/pdf6/p060008b.pdf Last accessed on 01-12-2008.

15. Pinto Slottow TL, Waksman R. Overview of the 2007 Food and Drug Administration Circulatory System Devices Panel meeting on the endeavor zotarolimus-eluting coronary stent. Circulation 2008;117:1603-8.

16. Meredith I, Worthley S, Whitbourn R, Walters D, Popma J, Cutlip D, Fitzgerald $\mathrm{P}$, on behalf of the Endeavor ${ }^{\mathrm{TM}}$ Resolute $^{\mathrm{TM}}$ Investigators. The next-generation Endeavor Resolute stent: 4-month clinical and angiographic results from the Resolute first-in-man trial. Eurolnterv 2007;3:50-3.

17. Stone GW, Midei M, Newman W, Sanz M, Hermiller JB, Williams J, Farhat N, Mahaffey KW, Cutlip DE, Fitzgerald PJ, Sood P, Su X, Lansky AJ; SPIRIT III Investigators. Comparison of an everolimus-eluting stent and a paclitaxel-eluting stent in patients with coronary artery disease: a randomized trial. JAMA 2008;299:1903-13.

18. Finn AV, Joner M, Nakazawa G, Kolodgie F, Newell J, John MC, Gold HK, Virmani R. Pathological correlates of late drug-eluting stent thrombosis: strut coverage as a marker of endothelialization. Circulation 2007;115:2435-41.

19. Palmaz JC, Benson A, Sprague EA. Influence of surface topography on endothelialization of intravascular metallic material. J Vasc Interv Radiol 1999;10:439-44.

20. Hecker JF, Scandrett LA. Roughness and thrombogenicity of the outer surfaces of intravascular catheters. J Biomed Mater Res 1985;19:381-95.

21. Daemen J, Serruys PW. Drug-eluting stent update 2007: part I. A survey of current and future generation drug-eluting stents: meaningful advances or more of the same? Circulation 2007;116:316-28.

22. Schwartz RS, Edelman ER, Carter A, Chronos N, Rogers C, Robinson KA, Waksman R, Weinberger J, Wilensky RL, Jensen DN, Zuckerman BD, Virmani R; Consensus Committee Drug-eluting stents in preclinical studies: recommended evaluation from a consensus group. Circulation 2002;106:1867-73.

23. Ormiston J, Panther M, Pornratanarangsi S, et al. The "Pitiful polymer, scanning electron microscope observations". TCT 2005, http://www.tctmd.com.

24. FDA Summary of Safety and Effectiveness Data Endeavor. http://www.fda.gov/cdrh/pdf6/p060033b.pdf. P060033, 21. 10-10-2007. Last accessed on 01-12-2008. 
25. Kandzari DE, Leon MB, Popma JJ, Fitzgerald PJ, O'Shaughnessy C, Ball MW, Turco M, Applegate RJ, Gurbel PA, Midei MG, Badre SS, Mauri L, Thompson KP, LeNarz LA, Kuntz RE; ENDEAVOR III Investigators. Comparison of zotarolimus-eluting and sirolimus-eluting stents in patients with native coronary artery disease: a randomized controlled trial. J Am Coll Cardiol 2006;48:2440-7.

26. Joner M, Finn AV, Farb A, Mont EK, Kolodgie FD, Ladich E, Kutys R, Skorija K, Gold HK, Virmani R.Pathology of drug-eluting stents in humans: delayed healing and late thrombotic risk. J Am Coll Cardiol 2006;48:193-202.

27. Bertrand OF, Faurie B, Larose E, Nguyen CM, Gleeton O, Déry JP, Noël B, Proulx G, Roy L, Costerousse O, De Larochellière R, Rodés-Cabau J. Clinical outcomes after multilesion percutaneous coronary intervention: comparison between exclusive and selective use of drug-eluting stents. J Invasive Cardiol 2008;20:99-104.

28. Barlis P, Kaplan S, Dimopoulos K, Ferrante G, Di Mario C. Comparison of bare-metal and sirolimus- or paclitaxel-eluting stents for aorto-ostial coronary disease. Cardiology 2008;111:270-6.

29. Virmani R, Guagliumi G, Farb A, Musumeci G, Grieco N, Motta T, Mihalcsik L, Tespili M, Valsecchi O, Kolodgie FD. Localized hypersensitiv- ity and late coronary thrombosis secondary to a sirolimus-eluting stent: should we be cautious? Circulation 2004;109:701-5.

30. Windecker S, Serruys PW, Wandel S, Buszman P, Trznadel S, Linke A, Lenk K, Ischinger T, Klauss V, Eberli F, Corti R, Wijns W, Morice MC, di Mario C, Davies S, van Geuns RJ, Eerdmans P, van Es GA, Meier B, Jüni P. Biolimus-eluting stent with biodegradable polymer versus sirolimus-eluting stent with durable polymer for coronary revascularisation (LEADERS): a randomised non-inferiority trial. Lancet 2008;372:1163-73.

31. Erbel R, Di Mario C, Bartunek J, for the PROGRESS-AMS Investigators. Temporary scaffolding of coronary arteries with bioabsorbable magnesium stents: a prospective, non-randomised multicentre trial. Lancet 2007;369:1869-75.

32. Serruys PW, Ormiston JA, Onuma Y, Regar E, Gonzalo N, GarciaGarcia HM, Nieman K, Bruining N, Dorange C, Miquel-Hébert K, Veldhof S, Webster M, Thuesen L, Dudek D. A bioabsorbable everolimus-eluting coronary stent system for patients with single de-novo coronary artery lesions (ABSORB): a prospective open-label trial. Lancet 2008;371:899-901.

33. Di Mario C, Ferrante G. Biodegradable drug-eluting stents: promises and pitfalls. Lancet 2008;371:874-5. 